\title{
Nutrition among men and household food security in an internally displaced persons camp in Kenya
}

\author{
Kamal P Singh*, Sankara Varun Bhoopathy, Heather Worth, Holly Seale and \\ Robyn L Richmond \\ School of Public Health and Community Medicine, University of New South Wales, Sydney, NSW 2052, Australia
}

Submitted 18 November 2013: Final revision received 15 February 2015: Accepted 25 February 2015: First published online 28 April 2015

\begin{abstract}
Objective: To determine the nutritional status of men and the food security status of their households in an internally displaced persons (IDP) camp in Kenya.

Design: A descriptive, cross-sectional study using a questionnaire and biometric measurements was completed in June 2013.

Setting: IDP camp, Rongai, Kenya.

Subjects: A total of 267 men aged $\geq 18$ years residing within the camp were recruited via respondent-driven sampling. Statistical associations between categorical variables were analysed using Pearson's $\chi^{2}$ tests, while independent $t$ tests were used for continuous variables.

Results: Among the men surveyed, we found a mean BMI of 20.3 (SD 2.5) kg/m², with $23.9 \%$ of participants in the underweight category $\left(\mathrm{BMI}<18.5 \mathrm{~kg} / \mathrm{m}^{2}\right)$. The mean Individual Dietary Diversity Score was 6 out of a maximum score of 9 . The mean Household Food Insecurity Access Scale score was 11.6 (SD 6.8), with 180 participants $(71.7 \%)$ residing in households categorised as severely food insecure. Low monthly household income $(<2000$ Kenyan Shillings, or \$US 25) was associated with a higher food insecurity score $(P<0 \cdot 001)$, greater likelihood of residing in a severely food-insecure household $(P<0.001)$, low dietary diversity score $(P<0.05)$ and being underweight $(P<0 \cdot 01)$.

Conclusions: While the nutritional status of men in the IDP camp is comparable to non-displaced men in Kenya, household food insecurity is relatively high. Efforts to improve food security for the future are essential to minimise the impact of severe food insecurity on mental health, disease profiles and family well-being reported in other IDP settings.
\end{abstract}

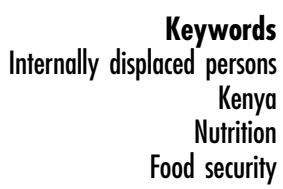

Internally displaced persons (IDP) are defined as persons who flee their place of residence due to armed conflict, situations of generalised violence, violation of human rights or natural or human-made disasters, without crossing a recognised international border ${ }^{(1)}$. Studies that have focused on displaced persons suggest that IDP continue to experience undernutrition with insufficient macronutrient and micronutrient intake ${ }^{(2)}$. Poor nutritional status was first correlated with increased mortality rates in the 1980s, most notable in Africa where displaced populations with the highest mortality rates also had the highest prevalence of acute undernutrition ${ }^{(3)}$. Although these associations were not definitively causative, it is extremely likely that the inadequate food aid supplies of this period were contributing to malnutrition, ill-health and mortality rates ${ }^{(4)}$. Quantity of food aid has since been increased from the 'survival' rations (5021-7531 kJ (1200-1800 kcal)/person per d) of the late 1980s to a single minimum target of
$8786 \mathrm{~kJ}$ (2100 kcal)/person per d for government and nongovernment organisations globally ${ }^{(4)}$. Although changes in nutrition practices may have led to a decline in malnutrition rates observed over time, the impact of undernutrition continues $^{(5)}$. This may be a result of the synergism between undernutrition and mortality rates due to acute and chronic disease, which still explains a significant portion of excess mortality among $\operatorname{IDP}^{(5,6)}$.

Food security is an evolving, composite concept which is said to exist 'when all people, at all times, have physical and economic access to sufficient safe and nutritious food to meet their dietary needs and food preferences for a healthy and active life ${ }^{,(7)}$. Three distinct aspects are critical to the attainment of food security: availability, access and utilisation of food $^{(8)}$. Food insecurity not only contributes to undernutrition across all ages, but is also a determinant of morbidity among IDP ${ }^{(9)}$. IDP with insufficient food security are more likely to report symptoms of post-traumatic stress 
disorder, depression and anxiety ${ }^{(10,11)}$. In the absence of a reliable source of food, women and girls are often forced into selling sex, placing them at risk of exploitation and $\mathrm{HIV}^{(12)}$. The hours spent by household adults searching for and completing daily work to purchase food compromises the care and well-being of children left at home ${ }^{(13)}$.

In 2007, disputed election results led to the outbreak of ethnic violence in Kenya. The violence was predominantly centred on the Rift Valley Province, where the Kikuyu minority, among others, were targeted. Government estimates state that up to 600000 people were displaced from their homes and eventually settled in IDP camps ${ }^{(14-16)}$. Reports suggest that access to basic needs including food, water, sanitation and health care continues to be irregular throughout Kenya's IDP camps ${ }^{(17)}$. To date, no study has been published about nutrition and food security among Kenya's IDP. The purpose of the present study was to determine the nutritional status of men and their household food security status in an IDP camp in Kenya. The aims were threefold: (i) to determine the nutritional status and dietary diversity among men, an under-researched population in IDP camps; (ii) to determine the food security status of households in an IDP camp in Kenya; and (iii) to relate the findings to the sociodemographic characteristics of the participants.

\section{Methods}

\section{Study area}

The present study was conducted in 2013 within an IDP camp located in Rongai District, Nakuru County, Kenya. The site is a resettlement camp for IDP displaced from the Rift Valley. Following the 2007/08 post-election violence, almost 10000 IDP from this area coalesced in makeshift camps at the Nakuru Showground. Within a year, they were provided 10000 Kenyan Shillings (KES; \$US 127) per household as compensation by the government, which they pooled together to purchase land in Nyandarua County. Many stayed within this settlement for up to three years (up to 2010) before being provided land by the government in Rongai. Currently, there are over 400 families residing in the study camp who have each been allocated 2 acres (0.81 ha) of land for agriculture and 0.25 acre $(0 \cdot 10 \mathrm{ha})$ of land for housing.

The study was undertaken over one week in June 2013, before the maize harvest when food supplies from the previous season were exhausted and food insecurity was high. This corresponds with the suggested time period for food security assessment in developing countries ${ }^{(18)}$.

The study was conducted according to the guidelines laid down in the Declaration of Helsinki and all procedures involving human subjects were approved by the University of New South Wales Human Research Ethics Committee (HREC Reference Number: HC 13157). Written informed consent was obtained from all subjects, with the help of an interpreter if necessary.

\section{Participants and data collection}

The study was cross-sectional, consisting of a questionnaire and biometric measurements. Participants were recruited via respondent-driven sampling. Respondent-driven sampling is considered a variant of chain-referral sampling, where the participants for a study are recruited by an initial sample of seeds ${ }^{(19)}$. The seeds are provided with documentation to recruit participants who then present in successive waves. The overall sample achieved is independent of the initial seeds from which sampling begins, hence respondentdriven sampling is considered a representative sampling technique ${ }^{(19,20)}$. The study utilised five seeds who were initially chosen by the camp chief and were deemed to have a wide social network within the IDP camp. Each seed was provided with three coupons to recruit other participants. Those recruited presented to the study site if they chose to participate; following which they were provided three more coupons to distribute among men they came in contact with in the camp. Men completing the study received a payment (50 KES or \$US 0.80) as reimbursement for their time. For each man who presented with a distributed coupon, the distributor was eligible for another $50 \mathrm{KES}$, collectable at the conclusion of the study. The data collected from the initial five seeds were discarded.

Inclusion criteria consisted of male gender, aged $\geq 18$ years, resident of the IDP camp and being physically and cognitively able to complete the questionnaire and biometric measurements. Men were excluded from the study if they were residents of neighbouring IDP camps.

Since the proportion of participants reporting each of the available responses in the questionnaire was unknown, a conservative approach was to assume a 50/50 split in responses across questions. The required sample size, with a $95 \%$ confidence interval, accounting for a finite population size of 400 men in the camp and to estimate responses with a precision of $\pm 5 \%$, was 197 .

\section{Questionnaire}

The questionnaire comprised seventy-two questions divided into three main areas: demographic characteristics, nutrition and food security. Demographic information collected included age, ethnicity, province of origin, employment and marital status. The nutrition and food security section incorporated three assessment scales (described below) identified through a literature review of similar studies conducted in the past. Questions were translated into Kiswahili, following which translated and English versions of the survey were uploaded onto Asus ME-400C Vivotab tablets using Questionnaire Design Studio (QDS) version 2·6·1 (Nova Research Company). The questionnaire was selfcompleted by participants in either English or Kiswahili with the optional use of an interpreter. 


\section{Individual Dietary Diversity Score}

The Individual Dietary Diversity Score (IDDS) is used as a proxy measure for nutrient intake ${ }^{(21)}$. The scale utilised in the present study was devised by the Food and Nutrition Technical Assistance Project (FANTA) at the US Agency for International Development. It has since been adapted and tested in Kenya, allowing it to be used without further modifications $^{(22)}$.

The IDDS asks participants about different food groups represented in their diet inside and outside of home over the previous $24 \mathrm{~h}$. Participants respond 'yes' (1) if they did consume food from a particular group or 'no' (0) if they did not, for a total of sixteen different groups. Their responses are then combined into nine food groups suggested by FANTA, as shown in Table $1^{(21,23)}$. Other remaining items such as sugar and tea were not used, as they were not deemed to add nutritional value to the diet. Participant responses were summed to provide a score out of 9 , with 0 representing minimum dietary diversity and 9 representing maximum dietary diversity. In the absence of universal dietary diversity cut-offs, we referred to the previously published literature ${ }^{(24,25)}$. This was used to categorise responses into low dietary diversity (score $\leq 4$ ) and high dietary diversity (score $>4$ ).

\section{Housebold Food Insecurity Access Scale}

The Household Food Insecurity Access Scale (HFIAS) is a measure to assess food security at the level of household access to food $^{(18)}$. The version utilised in the present study had already been adapted and tested in Kenya, and so was used without further modifications ${ }^{(22)}$.

Table 1 The nine food groups used to assess dietary diversity

\begin{tabular}{|c|c|}
\hline Food group & Examples \\
\hline Starchy staples & $\begin{array}{l}\text { Foods made from sorghum, millet, } \\
\text { maize, rice or wheat such as ugali } \\
\text { (thick maize porridge) or uji (thin } \\
\text { maize porridge) }\end{array}$ \\
\hline $\begin{array}{l}\text { Dark green leafy } \\
\text { vegetables }\end{array}$ & $\begin{array}{l}\text { Spinach, sweet potato leaves, moringa } \\
\text { leaves, cassava leaves, amaranthus, } \\
\text { kales, black nightshade, pumpkin } \\
\text { leaves }\end{array}$ \\
\hline $\begin{array}{l}\text { Other vitamin A-rich } \\
\text { fruits and vegetables }\end{array}$ & $\begin{array}{l}\text { Mangoes, papaya, pumpkin, carrots, } \\
\text { orange-fleshed sweet potatoes }\end{array}$ \\
\hline $\begin{array}{l}\text { Other fruits and } \\
\text { vegetables }\end{array}$ & $\begin{array}{l}\text { Tomatoes, onion, eggplant, cabbage, } \\
\text { brinjals, oranges, lemon, grapes, } \\
\text { guava }\end{array}$ \\
\hline Organ & Liver, kidney, heart, etc. \\
\hline Meat and fist & $\begin{array}{l}\text { Beef, pork, mutton, goat meat, rabbit } \\
\text { meat, chicken, duck or bird meat, } \\
\text { fresh or dried fish, omena, prawns, } \\
\text { Nile perch }\end{array}$ \\
\hline Eggs & Chicken, duck or any other bird eggs \\
\hline $\begin{array}{l}\text { Legumes, nuts and } \\
\text { seeds }\end{array}$ & $\begin{array}{l}\text { Beans, simsim, pigeon peas, cowpeas, } \\
\text { green gram, lentils, soyabeans, } \\
\text { groundnuts, cashew nuts, garden } \\
\text { peas, black beans, or any foods } \\
\text { made from those mentioned }\end{array}$ \\
\hline Milk and milk products & $\begin{array}{l}\text { Milk, fermented milk, cheese, yoghurt } \\
\text { etc. }\end{array}$ \\
\hline
\end{tabular}

The scale consists of nine items which follow a progression that begins with anxiety about food, a decrease in quality and quantity of food, and finally going to sleep hungry and going all day and night without eating. Participants are asked to respond with a 'yes' or 'no' to each item. If they respond 'yes' they are then asked to specify whether the experience occurs rarely (once or twice in the past month), sometimes (three to ten times in the past month) or often (more than ten times in the past month). Responses were scored so that 'no' received a score of 0 , 'rarely' scored 1, 'sometimes' scored 2 and 'often' scored 3. By summing the code for each question, a score out of 27 was calculated for each participant, where a higher score represented greater food insecurity. Responses were also organised into food security categories (from food secure to severely food insecure) according to their most severe response as recommended by the HFIAS indicator guide ${ }^{(18)}$.

\section{Household Hunger Scale}

The Household Hunger Scale (HHS) is a newly emerging measure of hunger in regions which may already be experiencing significant food insecurity ${ }^{(26)}$. The HHS is composed of the final three items of the HFIAS, which have been specifically validated for cross-cultural use ${ }^{(27)}$. Parameters of the HHS were also analysed and included in the current report as preliminary analysis suggested a significant degree of food insecurity. The values obtained from the final three items in the HFIAS were recoded ('no' $=0$, 'rarely' or 'sometimes' $=1$ and 'often' =2) and summed to provide a score out of 6 . Responses were then placed in categories of household hunger from little or no hunger (score 0-1) to moderate hunger (score 2-3) and severe hunger (score 4-6) ${ }^{(26)}$.

\section{Biometric measurements}

Nutritional assessment of adults remains a difficult undertaking due to a lack of consensus on assessment techniques in emergency situations ${ }^{(28)}$. The currently recommended techniques for assessment of adult undernutrition are BMI and mid-upper arm circumference (MUAC) $^{(3,28)}$. For BMI, height was determined using the Seca 206 Mechanical Tape Measure and weight was determined using the Omron HBF-202 Body Composition Scale. MUAC was measured using a constant tension tape measure. Normal BMI was taken as $\geq 18.5 \mathrm{~kg} / \mathrm{m}^{2}$, below which an individual was considered to be undernourished, whether grade I $\left(17 \cdot 0-18 \cdot 4 \mathrm{~kg} / \mathrm{m}^{2}\right)$, grade II $\left(16 \cdot 0-16 \cdot 9 \mathrm{~kg} / \mathrm{m}^{2}\right)$ or grade III $\left(\leq 15 \cdot 9 \mathrm{~kg} / \mathrm{m}^{2}\right)$ thinness ${ }^{(29)}$. A MUAC reading of $\leq 18.5 \mathrm{~cm}$ was used to define undernutrition $^{(28)}$.

\section{Data analysis}

Data were analysed using the statistical software package IBM SPSS (v21.0) for Windows (2012) and Epi Info (v7·1.2) 
for Windows (2013). Statistical associations of categorical variables, including category of dietary diversity, household hunger and food security, with relevant demographic variables were analysed using Pearson's $\chi^{2}$ tests. Crude odds ratios have been reported throughout, using demographic variables as exposure and measures of dietary diversity and food security as outcomes. Associations of continuous variables, including sum of IDDS, HHS and HFIAS, with relevant demographic categories were analysed by using independent $t$ tests. A $P$ value of $<0.05$ was considered significant. Data were found to be non-parametric and followed a normal distribution due to the large sample size.

\section{Results}

Of the 267 participants who took part in the study between 22 June 2013 and 29 June 2013, 251 responses were included in the analysis. The QDS data files for sixteen participants became corrupted and so were unusable.

\section{Demographic characteristics}

The mean age of participants was 37 (SD 16.0) years, $84.5 \%$ were of Kikuyu ethnicity and $82.1 \%$ had resided in the former Rift Valley Province prior to displacement. The other major ethnic groups were Kisii $(7 \cdot 2 \%, n$ 18), Luhya $(2 \cdot 8 \%, n 7)$, Kalenjin $(2 \cdot 4 \%, n 6)$ and Kamba $(1 \cdot 2 \%, n 3)$. Three-fifths of participants had completed up to or more than primary education, half were married and the mean household size was 7 (SD 4.7). Half were employed (predominantly in agriculture) and the median monthly household income was 2500 KES (\$US 32). Table 2 shows the full demographic characteristics of the participants.

\section{Dietary patterns}

During the past 12 months, most participants (95.2\%, $n$ 239) consumed at least one meal every day. Those who ate less frequently reported that they consumed a meal several times per week ( $n$ 6), once per week $(n 1)$ and four respondents reported eating a meal a few times per month. The most common food source was from own production $(63.7 \%, n 160), 28.3 \%$ ( $n 71)$ consumed food from own purchases, while eleven participants ( $4.4 \%)$ relied upon food from friends/relatives and a further nine (3.6\%) depended on food aid from government. The majority $(86 \cdot 1 \%, n 216)$ reported accessing more than one of the above listed sources of food. When asked about cooking fuel, almost all of those surveyed (92.8\%, $n$ 233) did not feel their household had ready access.

\section{Food security}

Housebold Food Insecurity Access Scale

Responses to the nine items of the HFAIS are shown in Table 3. The item with the greatest percentage of 'yes'
Table 2 Demographic characteristics of men $(n$ 251) at the internally displaced persons camp included in the study, Rongai, Kenya, June 2013

\begin{tabular}{|c|c|c|}
\hline Characteristic & Mean or $n$ & SD or \% \\
\hline Age (years) ${ }^{*}$ & 37 & 16 \\
\hline \multicolumn{3}{|l|}{ Ethnicity† } \\
\hline Kikuyu & 212 & 84.5 \\
\hline Other & 39 & $15 \cdot 5$ \\
\hline \multicolumn{3}{|l|}{ Education† } \\
\hline No schooling/primary school incomplete & 90 & 35.9 \\
\hline Primary school & 101 & $40 \cdot 2$ \\
\hline Secondary school & 55 & 21.9 \\
\hline College/university & 3 & $1 \cdot 2$ \\
\hline Not specified & 2 & 0.8 \\
\hline \multicolumn{3}{|l|}{ Province of origint } \\
\hline Rift Valley & 206 & $82 \cdot 1$ \\
\hline Central & 25 & $10 \cdot 0$ \\
\hline Other & 20 & 7.9 \\
\hline \multicolumn{3}{|l|}{ Relationship status $\dagger$} \\
\hline Currently married/living together & 143 & $57 \cdot 0$ \\
\hline Never married & 79 & 31.5 \\
\hline Other & 41 & $16 \cdot 3$ \\
\hline \multicolumn{3}{|l|}{ Employment over preceding 12 months $\dagger$} \\
\hline Employed & 124 & $49 \cdot 4$ \\
\hline Agriculture & 94 & 37.5 \\
\hline Sales/services & 11 & 4.4 \\
\hline Other & 19 & 7.5 \\
\hline Unemployed (able to work) & 121 & $48 \cdot 2$ \\
\hline Unemployed (unable to work) & 5 & $2 \cdot 0$ \\
\hline Other & 1 & 0.6 \\
\hline \multicolumn{3}{|c|}{ Monthly household income over preceding 12 months (KES) $\dagger$} \\
\hline 0-2000 (\$US 0-25) & 120 & $47 \cdot 8$ \\
\hline 2001-4000 (\$US 25-60) & 59 & 23.5 \\
\hline$>4000(\$ \cup S>60)$ & 64 & $25 \cdot 5$ \\
\hline Don't know & 5 & $2 \cdot 0$ \\
\hline Refuse to answer & 3 & $1 \cdot 2$ \\
\hline Number of people at home* & $7 \cdot 0$ & $4 \cdot 7$ \\
\hline Number of children at home ${ }^{*}$ & 3.5 & 3.0 \\
\hline
\end{tabular}

KES, Kenyan Shillings.

*Data are presented as mean and standard deviation.

†Data are presented as absolute number and percentage of the total.

responses was item 3, having to limit the variety of foods eaten, which was reported by $80 \cdot 5 \%$ ( $n$ 202) of participants. This was followed by the closely related item 2 , missing out on preferred foods, experienced by $79.3 \%$ ( $n$ 199). The item with the least number of 'yes' responses, going a whole day and night without eating (item 9), was also the severest. It was reported by $49.0 \%$ ( $n$ 123) of participants.

Having to reduce the variety of foods (item 3) and missing out on preferred foods (item 2 ) were also the most frequently reported, with $22 \cdot 3 \%$ ( $n$ 56) and $21 \cdot 1 \%$ ( $n$ 53), respectively, experiencing them often (more than ten times in the past four weeks). They were followed by eating unwanted foods (item 4 experienced often by $16.7 \%$ ) and eating fewer meals or smaller meals in a day, experienced often by $15 \cdot 1 \%(n$ 38) and $13.5 \%(n 34)$, respectively. The least frequently experienced item was item 9, going a whole day and night without eating, which in most cases occurred rarely $(22.7 \%)$ followed by sometimes $(21.5 \%)$, although twelve participants $(4.8 \%)$ reported it often within their household. 
Table 3 Responses to the nine items of the Household Food Insecurity Access Scale among men $(n$ 251) at the internally displaced persons camp included in the study, Rongai, Kenya, June 2013

If yes, how often in the past 4 weeks? (\%)

HFIAS item $\%$ yes Rarely* Sometimes† Often $\ddagger$

Because of a lack of food or resources to obtain food, in the past 4 weeks...

1. Did you fear that your household would lack enough food?

2. Were you or any household member not able to eat the kinds of foods you preferred?

3. Did you or any household member have to eat a limited variety of foods?

4. Did you or any household member have to eat some foods you really did not want to eat?

5. Did you or any household member have to eat a smaller meal than you felt you needed?

6. Did you or any other household member have to reduce the number of meals you ate in a day?

7. Was there ever no food to eat of any kind in your household?

8. Did you or any household member go to sleep at night hungry?

9. Did you or any household member go a whole day and night without eating anything?

$74 \cdot 1 \quad 29 \cdot 9$

$79.3 \quad 27.5$

$80.5 \quad 25.5$

$74.9 \quad 23.9$

$74.5 \quad 27.9$

$71.7 \quad 28.3$

$62.2 \quad 28.7$

$62.5 \quad 28.7$

$49.0 \quad 22.7$
$32 \cdot 7 \quad 11.6$

$30.7 \quad 21.2$

$32.7 \quad 22.3$

$34.3 \quad 16.7$

33. 13.5

$29.3 \quad 15 \cdot 1$

$26.3 \quad 7.2$

$27.9 \quad 6.0$

$21.5 \quad 4.8$

*Once or twice in the past 4 weeks.

†Three to ten times in the past 4 weeks.

$\ddagger$ More than ten times in the past 4 weeks.

The mean HFIAS score was 11.6 (SD 6.8), with scores ranging from 0 (food security) to 27 (maximum food insecurity). HFIAS score was associated with income. Those earning less than 2000 KES (\$US 25) per month had a significantly $(P<0.001)$ higher mean HFIAS score (14.26) than the mean (9.26) for others, suggesting greater food insecurity. The majority of participants $(71.7 \%)$ were from severely food-insecure households, $13.5 \%$ were moderately food insecure, $4 \cdot 8 \%$ were mildly food insecure while only $4.8 \%$ were food secure.

Income was associated with severity of household food insecurity, with those earning less than $2000 \mathrm{KES}$ (\$US 25) per month (OR $=7 \cdot 3$; $95 \%$ CI $2 \cdot 1,25 \cdot 7, P<0 \cdot 001)$ more likely to report severe household food insecurity. Similarly, household size was also associated, as those with more than three children at home $(\mathrm{OR}=1.9 ; 95 \% \mathrm{CI} 1 \cdot 001,3 \cdot 5$, $P<0.05)$ were more likely to be categorised as living in severely food-insecure households.

\section{Household Hunger Scale}

Items 7, 8 and 9 from the HFIAS outlined in Table 3 were analysed separately to produce the HHS. The median HHS score was 2 (SD 1.5) out of a maximum possible score of 6 . The most common condition of household hunger reported in the past four weeks was going to sleep hungry, which was reported to have occurred at least once by $62.5 \%$ ( $n$ 157). The condition experienced most often in the past four weeks was having no food of any kind in the household, which eighteen participants (7.2\%) experienced more than ten times. The majority of participants were from households with moderate hunger (46.6\%), followed by little or no hunger (40.2\%) and severe hunger (10.0\%).

Men aged over 45 years $(\mathrm{OR}=2 \cdot 4 ; 95 \%$ CI 1.04, 5.7, $P<0.05)$ and from households earning less than $2000 \mathrm{KES}$ (\$US 25) per month (OR=3.7; $95 \%$ CI 1.4, 9.7, $P<0 \cdot 01$ ) were more likely to report being in the severe household hunger category.

\section{Dietary diversity}

The results of the IDDS are presented in Table 4. Starchy staples (e.g. thick maize porridge ugali, and thin maize porridge $u j i$ ) were the most commonly consumed food group in the preceding $24 \mathrm{~h}$, eaten by $92.0 \%$ of participants. Organ meat (e.g. liver, heart and kidney) was the least common, consumed by only $21.9 \%$. When responses were summed to provide a score out of 9 , the mean IDDS was 6 (SD 1.8).

Low dietary diversity (score $\leq 4$ ) was associated with income, food insecurity and household hunger. Participants who reported monthly household income under $2000 \mathrm{KES}$ or $\$$ US 25 (OR $=2 \cdot 2$; $95 \%$ CI $1 \cdot 1,4 \cdot 5, P<0 \cdot 05$ ) and those residing in households with severe hunger (OR $=3.7 ; 95 \%$ CI 1.5, 9.0, $P<0.01$ ) were more likely to have low dietary diversity. Those with low dietary diversity also had a significantly $(P<0 \cdot 001)$ higher mean HFIAS score $(15 \cdot 18)$ than those with high dietary diversity (11.02). Among participants with low diversity scores ( $n$ 45), the majority $(82.2 \%)$ consumed starchy staples in the preceding $24 \mathrm{~h}$, while very few consumed organ meat ( $4.4 \%)$, other meat and fish (8.9\%) and eggs (2.2\%).

\section{Biometric measurements}

Biometric measurements were collected on all participants including BMI and MUAC; a summary of results is presented in Table 5 . The mean BMI was 20.3 (sD $2 \cdot 5$ ) $\mathrm{kg} / \mathrm{m}^{2}$. The majority of participants $(68.9 \%)$ had a normal BMI, while approximately a quarter (23.9\%) were underweight. Of those underweight ( $n$ 60), 85.0\% had mild thinness $\left(\mathrm{BMI}=17 \cdot 0-18 \cdot 4 \mathrm{~kg} / \mathrm{m}^{2}\right), 13 \cdot 3 \%$ had moderate thinness $\left(\mathrm{BMI}=16 \cdot 0-16.9 \mathrm{~kg} / \mathrm{m}^{2}\right)$ and a single participant had severe thinness $\left(B M I \leq 15.9 \mathrm{~kg} / \mathrm{m}^{2}\right)$.

BMI was associated with age, income and marital status. Those aged over 40 years were more likely to have a BMI in the underweight category $(\mathrm{OR}=1 \cdot 9 ; 95 \% \mathrm{CI} 1 \cdot 06,3 \cdot 5$, $P<0 \cdot 05)$. Men from households with a combined monthly 
Table 4 Percentage having consumed food from a particular food group in the preceding $24 \mathrm{~h}$ among men $(n 251)$ at the internally displaced persons camp included in the study, Rongai, Kenya, June 2013

\begin{tabular}{lccc}
\hline & & \% of participants having eaten in the last 24 $\mathrm{h}$ \\
\cline { 2 - 4 } Food group & Total $(n$ 251) & $\begin{array}{c}\text { Low dietary diversity* } \\
(n \text { 45) } \dagger\end{array}$ & $\begin{array}{c}\text { High dietary diversity } \\
(n \text { 182) } \dagger\end{array}$ \\
\hline 1. Starchy staples & 92.0 & 82.2 & 96.2 \\
2. Dark green leafy vegetables & 79.3 & 53.3 & 89.0 \\
3. Other vitamin A-rich fruits and vegetables & 78.5 & 42.2 & 87.9 \\
4. Other fruits and vegetables & 83.7 & 55.6 & 92.3 \\
5. Organ meat & 21.9 & 4.4 & 29.1 \\
6. Meat and fish & 47.8 & 8.9 & 57.7 \\
7. Eggs & 40.2 & 2.2 & 51.6 \\
8. Legumes, nuts and seeds & 77.7 & 57.8 & 85.7 \\
9. Milk and milk products & 76.9 & 51.1 & 87.9 \\
\hline
\end{tabular}

${ }^{*}$ Defined as an Individual Dietary Diversity Score (IDDS) of $\leq 4$ out of 9 .

†While 251 participants completed the IDDS in total, not all placed a response for every food group. Hence IDDS could not be calculated for these respondents and so they could not be categorised as having low or high dietary diversity $(n 24)$.

$\ddagger$ Defined as an IDDS of $>4$ out of 9 .

Table $5 \mathrm{BMl}$ and mid-upper arm circumference (MUAC) of men ( $n$ 251) at the internally displaced persons camp included in the study, Rongai, Kenya, June 2013

\begin{tabular}{lcr}
\hline Characteristic & $n$ or Mean & \% or SD \\
\hline BMI category* & & \\
Underweight $\left(<18.5 \mathrm{~kg} / \mathrm{m}^{2}\right)$ & 60 & 23.9 \\
Grade I (mild) thinness & 51 & 20.4 \\
Grade II (moderate) thinness & 8 & 3.1 \\
Grade III (severe) thinness & 1 & 0.4 \\
Normal $\left(18.5-24.9 \mathrm{~kg} / \mathrm{m}^{2}\right)$ & 173 & 68.9 \\
Overweight $\left(25.0-29.9 \mathrm{~kg} / \mathrm{m}^{2}\right)$ & 15 & 6.0 \\
Obese $\left(\geq 30.0 \mathrm{~kg} / \mathrm{m}^{2}\right)$ & 1 & 0.4 \\
MUAC $(\mathrm{cm}) \dagger$ & 26.4 & 2.7 \\
\hline
\end{tabular}

*Data are presented as absolute number and percentage of the total. †Data are presented as mean and standard deviation.

income less than $2000 \mathrm{KES}$ (\$US 25) were more likely to have an underweight $\mathrm{BMI}(\mathrm{OR}=2 \cdot 3 ; 95 \% \mathrm{CI} 1 \cdot 2,4 \cdot 2$, $P<0.01)$, as were those who were currently married or living together $(\mathrm{OR}=2 \cdot 2 ; 95 \% \mathrm{CI} 1 \cdot 2,4 \cdot 1, P<0 \cdot 01)$.

The mean MUAC was $26.4 \mathrm{~cm}(\mathrm{SD} 2 \cdot 7) \mathrm{cm}$, and ranged from $20.5 \mathrm{~cm}$ to $36.5 \mathrm{~cm}$. No participant was below the $18.5 \mathrm{~cm}$ cut-off suggested for undernutrition among adults affected by emergency situations ${ }^{(28)}$.

\section{Discussion}

To our knowledge, the present study is the first to analyse nutrition and food security among individuals displaced in the 2007/08 Kenyan post-election violence. Although research on this topic has been completed among IDP in other regions, the present study provides new information by: (i) determining the nutritional status of men who are typically neglected in nutrition assessments; and (ii) using standardised food security assessment scales which have been used in other regions to allow comparison with nondisplaced populations.
Our study found that men at the camp had a mean BMI of $20 \cdot 3(\mathrm{sD} 2 \cdot 5) \mathrm{kg} / \mathrm{m}^{2}$, with $23.9 \%$ of participants underweight $\left(\mathrm{BMI}<18.5 \mathrm{~kg} / \mathrm{m}^{2}\right)$. These findings are relatively similar to other studies among non-displaced men in rural Kenya ${ }^{(30,31)}$. This is in contrast with literature in other regions which has suggested that IDP generally have poorer nutritional status than surrounding, comparable non-displaced populations ${ }^{(32-34)}$. We hypothesise there may be many reasons for this difference. Notably, previous studies have been completed earlier following displacement when instability, disease and food shortages may be more widespread. Our study was completed five years following displacement in a relatively stable and welldeveloped camp. Perhaps more importantly, households at the camp have been allocated 2 acres ( 0.81 ha) of agricultural land each, reducing reliance on food aid which has been unreliable and insufficient in other regions ${ }^{(6,35)}$.

Our research suggests that BMI and MUAC are not equivalent measures of undernourishment among adults. This is because MUAC, unlike BMI, does not have defined cut-offs $^{(30)}$. While our study utilised the updated cut-off value of $18.5 \mathrm{~cm}$, researchers continue to use the previously suggested $23.0 \mathrm{~cm}^{(28,36)}$. If a cut-off of $23.0 \mathrm{~cm}$ had been utilised, nineteen participants (7.6\%) would have been classified as undernourished according to MUAC. Consensus regarding cut-offs will assist the use and interpretation of MUAC as a tool for assessment of undernourished adults.

In our study, the mean HFIAS score was 11.6 with 180 $(71.7 \%)$ participants reporting severe food insecurity within their household. When compared with other studies, levels of food insecurity among camp households are more similar to vulnerable populations affected by HIV and AIDS than to average rural settings in the region ${ }^{(37,38)}$. We hypothesise this may, to some extent, be due to the lack of household capital to support agriculture. Although households at this camp have been provided 2 acre (0.81 ha) plots of land, discussions with community 
members suggest that lack of income means that fertiliser, agricultural implements and seeds are still difficult to access. This limits cultivation to maize and beans, which are used to prepare the staple foods ugali (thick maize porridge) and githeri (maize and kidney beans). This was reflected in responses to HFIAS items, where eating just a few kinds of foods or being unable to eat preferred foods were the most frequent and widespread experiences of food insecurity. Furthermore, those with lower monthly income, as expected, reported higher food insecurity and were more likely to reside in a household categorised as severely food insecure. In contrast, those with higher monthly income may be able to invest in the cultivation of more land, grow a greater diversity of crops and utilise other sources of food including the market and livestock, leading to improved food security.

Among IDP in other regions, food insecurity has led to women selling sex, placing them at risk of gender exploitation and $\mathrm{HIV}^{(12)}$. Food insecurity has also been linked to symptoms of post-traumatic stress disorder, depression and anxiety ${ }^{(10,11)}$. Symptoms of anxiety and depression have already been reported as incidental findings in other research among Kenyan IDP; whether this is associated with food insecurity may be of interest to future studies ${ }^{(39)}$.

Most of our participants were categorised into moderate household hunger (46.6\%) followed by little or no hunger (40.2\%) and severe hunger (10.0\%). Initial comparison suggests that the hunger profile of households at this camp is relatively similar to results obtained from non-displaced populations in Mozambique and Malawi ${ }^{(27)}$. The percentage of households reporting severe household hunger is higher among people living with HIV and AIDS in Zimbabwe, and among non-displaced persons in South Africa, possibly also due to high rates of $\mathrm{HIV}^{(27)}$. It is, however, difficult to elaborate further on the results we have obtained. This is because the HHS is an emerging measure of household food deprivation that has not been used or documented as widely as the HFIAS. Our findings will become easier to interpret, and serve as a point of comparison, as future studies using this scale are published.

We found a mean dietary diversity score of six out of nine food groups. Unfortunately, studies determining the dietary diversity score in adults residing in Kenya are limited. In a study from the provinces of South Africa, the mean dietary diversity score ( $n$ 3287) across all nine provinces was $4.02^{(25)}$. It ranged from 3.24 in Limpopo Province ( $n$ 306) to 4.78 in the Western Cape ( $n$ 441). Similar to our findings, the most common food group consumed among adult South Africans was also starchy staples, although reported consumption of virtually all eight remaining food groups was higher among men at the camp. Based on this comparison, it would appear that dietary diversity among men residing in the camp is higher than reported among adults in South Africa. This may be linked to the differences in main sources of food. Those at the camp relied on their own production for food. In addition to their 2 acre ( 0.81 ha) agricultural plots, they were able to plant small amounts of vegetables on their 0.25 acre $(0.10 \mathrm{ha})$ residential plots. In contrast, the majority of participants in the South African study relied on own purchases, often using money from low-paying occupations. Low-income households relying on purchases are more likely to prefer low-cost, energy-dense foods rather than consume a wide variety of micronutrientrich foods ${ }^{(40,41)}$. However, our finding of relatively high dietary diversity contrasts with the high percentage of 'yes' responses to HFIAS items 2 and 3, which both relate to diversity of dietary intake. There may be a number of reasons for this apparent contradiction. Participants in our study may have misinterpreted the $24 \mathrm{~h}$ recall period for the IDDS and reported with reference to a longer recall period. The South African study also included women in their sample size while we did not, and it may be true that women have lower dietary diversity than their male counterparts. Further repeat research in IDP camps in Kenya may be needed to confirm our findings.

We also found that those with low dietary diversity reported a monthly income below 2000 KES (\$US 25), a higher mean HFIAS score (hence greater food insecurity) and were more likely to report severe household hunger. This is similar to findings in another study in South Africa where an inverse relationship between food insecurity and dietary diversity was documented ${ }^{(24)}$. It has already been established in other settings that dietary diversity scores are positively correlated with adequate macronutrient and micronutrient intakes across all ages, including adults ${ }^{(42-44)}$. It is therefore likely that residents in food-insecure households may be eating a diet of less nutritional adequacy compared with food-secure households, which may have implications for future health and well-being.

A key strength of the present study was the use of a recruitment technique that yielded a diverse population in a relatively short period of time. The cross-sectional nature of the study makes it difficult to draw causal relationships and can be seen as a limitation. Also, the research focused on a single camp that was particularly well established. These findings may not be similar in other IDP camps in Kenya, particularly those where land allocation has not been completed. By focusing on men over 18 years, female-headed households with small children were excluded. Such households in other settings have been found to report greater food insecurity ${ }^{(38)}$.

Thus our study suggests that the nutritional status of men at the IDP camp is comparable to that of nondisplaced men in Kenya. However, the same cannot be said for the alarming levels of household food insecurity. Five years on from the original episode of displacement, households at the camp continue to experience food insecurity at a level comparable to other vulnerable populations (such as people living with HIV and AIDS) in 
Kenya and sub-Saharan Africa. Recommendations to improve food security include registering land allocations under the name of the owner to provide access to credit and encourage investment in agricultural implements. This could be complemented with education programmes to provide information about planting and harvesting practices for improved yields. Such steps will be essential to address severe food insecurity and minimise its impact on mental health, disease profiles and family well-being documented in other IDP settings.

\section{Acknowledgements}

Acknowledgements: The authors are thankful for the assistance with data collection provided by Dr Zubair Hasan, Ms Audrey Maag, Ms Lauren Middlebrook and Ms Paola Lupica. They are grateful to Dr Patrick Rawstorne of the School of Public Health and Community Medicine, University of New South Wales for assistance using QDS and to Dr Elizabeth Kpozehouen for assistance with translation. They thank the residents and households of this IDP camp for participating in this study. Financial support: This research received no specific grant from any funding agency in the public, commercial or not-for-profit sectors. Conflict of interest: None. Authorship: Research design and data collection were the combined effort of all authors. K.P.S. was involved in data analysis and writing with substantial input from R.L.R., H.W. and H.S. regarding statistical methods, feedback on writing and interpretation of results. Ethics of human subject participation: Ethics approval was obtained from the University of New South Wales Human Research Ethics Committee (HREC Reference Number: HC 13157).

\section{References}

1. Deng F (1999) Guiding principles on internal displacement. Int Migr Rev 33, 484-493.

2. Bhatia R \& Richardson L (2005) Refugees. In Encyclopedia of Human Nutrition, 2nd ed., pp. 87-96 [C Benjamin, editor]. Oxford: Elsevier.

3. Young H, Borrel A, Holland D et al. (2004) Public nutrition in complex emergencies. Lancet 364, 1899-1909.

4. Mason J (2002) Lessons on nutrition of displaced people. $J$ Nutr 132, issue 7, 2096S-2103S.

5. Bhatia R \& Thorne-Lyman A (2003) Food aid in emergencies and public health nutrition. Forum Nutr 56, 391-394.

6. Toole M (1995) Mass population displacement. A global public health challenge. Infect Dis Clin North Am 9, 353-366.

7. Pinstrup-Andersen P (2009) Food security: definition and measurement. Food Sec 1, 5-7.

8. Shetty P (2007) Achieving the goal of halving global hunger by 2015. Proc Nutr Soc 65, 7-18.

9. Roberts B, Ocaka K, Browne J et al. (2009) Factors associated with the health status of internally displaced persons in northern Uganda. J Epidemiol Community Health 63, 227-232.

10. Cardozo B, Bilukha O, Crawford C et al. (2004) Mental health, social functioning, and disability in postwar Afghanistan. JAMA 292, 575-584.
11. Hamid A \& Musa S (2010) Mental health problems among internally displaced persons in Darfur. Int J Psychol 45, 278-285.

12. Bukuluki P, Mugumya F, Neema S et al. (2008) Gender, Food Security and AIDS in Internally Displaced People's Camps in Uganda. Washington, DC: International Food Policy Research Institute.

13. Olwedo M, Mworozi E, Bachou H et al. (2008) Factors associated with malnutrition among children in internally displaced persons' camps, northern Uganda. Afr Health Sci 8, 244-252.

14. Shutzer M (2012) The politics of home: displacement and resettlement in postcolonial Kenya. Afr Stud 71, 346-360.

15. Kamungi P (2009) The politics of displacement in multiparty Kenya. J Contemp Afr Stud 27, 345-364.

16. Klopp J, Githinji P \& Karuoya K (2010) Internal Displacement and Local Peacebuilding in Kenya: Challenges and Innovations. Washington, DC: US Institute of Peace.

17. Beyani C (2012) Report of the Special Rapporteur on the Human Rights of Internally Displaced Persons. Mission to Kenya. New York: UN Human Rights Council.

18. Coates J, Swindale A \& Bilinsky P (2007) Household Food Insecurity Access Scale (HFIAS) for Measurement of Food Access: Indicator Guide. Washington, DC: Food and Nutrition Technical Assistance Project, Academy for Educational Development.

19. Heckathorn D (1997) Respondent-driven sampling: a new approach to the study of hidden populations. Soc Probl 44, 174-199.

20. Salganik M \& Heckathorn D (2004) Sampling and estimation in hidden populations using respondent-driven sampling. Sociol Methodol 34, 193-240.

21. Kennedy G, Ballard T \& Dop M (2013) Guidelines for Measuring Household and Individual Dietary Diversity. Rome: FAO.

22. Mwangi A \& Mbera G (2006) Report of the Adaptation and Pre-Testing of Household Food Security Monitoring Tools: The Kenya Experience. Nairobi: University of Nairobi Applied Nutrition Program.

23. Swindale A \& Bilinsky P (2006) Household Dietary Diversity Score (HDDS) for Measurement of Housebold Food Access: Indicator Guide. Washington, DC: Food and Nutrition Technical Assistance Project, Academy for Educational Development.

24. Faber M, Schwabe C \& Drimie S (2009) Dietary diversity in relation to other household food security indicators. Int $J$ Food Saf Nutr Public Health 2, 1-15.

25. Labadarios D, Steyn N \& Nel J (2011) How diverse is the diet of adult South Africans? Nutr J 10, 33-44.

26. Ballard T, Coates J, Swindale A et al. (2011) Household Hunger Scale: Indicator Definition and Measurement Guide. Washington, DC: Food and Nutrition Technical Assistance Project, Academy for Educational Development.

27. Deitchler M, Ballard T, Swindale A et al. (2010) Validation of a Measure of Household Hunger for Cross-Cultural Use. Washington, DC: Food and Nutrition Technical Assistance Project, Academy for Educational Development.

28. Collins S, Duffield A \& Myatt M (2000) Assessment of Nutritional Status in Emergency-Affected Populations. Geneva: UN Administrative Committee on Coordination/ Subcommitee on Nutrition.

29. Ferro-Luzzi A, Sette S, Franklin M et al. (1992) A simplified approach of assessing adult chronic energy deficiency. EurJ Clin Nutr 46, 173-186.

30. Jayne J, Scrimgeour AG, Polhemus ME et al. (2011) Dietary and socio-economic correlates of nutritional status in a rural adult Kenyan population. Afr J Food Agric Nutr Dev 11, 5035-5052.

31. Hansen A, Christensen D, Larsson M et al. (2011) Dietary patterns, food and macronutrient intakes among adults in 
three ethnic groups in rural Kenya. Public Health Nutr 14, 1671-1679.

32. Guerrier G, Zounoun M, Delarosa O et al. (2009) Malnutrition and mortality patterns among internally displaced and non-displaced population living in a camp, a village or a town in Eastern Chad. PLoS One 4, e8077.

33. Lambert M, Brown V, Villagi F et al. (1994) Malnutrition in displaced persons in Zaire. Lancet 343, 1296.

34. Nyuar K, Khalil A \& Crawford M (2012) Dietary intake of Sudanese women: a comparative assessment of nutrient intake of displaced and non-displaced women. Nutr Health 21, 131-144.

35. Kim G, Torbay R \& Lawry L (2007) Basic health, women's health, and mental health among internally displaced persons in Nyala Province, South Darfur, Sudan. Am J Public Health 97, 353-361.

36. Ferro-Luzzi A \& James W (1996) Adult malnutrition: simple assessment techniques for use in emergencies. Br J Nutr 75, 3-10.

37. Knueppel D, Demment M \& Kaiser L (2010) Validation of the household food insecurity access scale in rural Tanzania. Public Health Nutr 13, 360-367.
38. Ndirangu M, Sachs S, Palm C et al. (2013) HIV affected households in Western Kenya experience greater food insecurity. Food Policy 42, 11-17.

39. Bamrah S, Mbithi A, Mermin J et al. (2013) The impact of postelection violence on HIV and other clinical services and on mental health - Kenya, 2008. Prehosp Disaster Med 28, 43-51.

40. Marmot M \& Wilkinson R (2005) Social Determinants of Health, 2nd ed. New York: Oxford University Press.

41. De Irala-Estevez J, Groth M, Johansson L et al. (2000) A systematic review of socio-economic differences in food habits in Europe: consumption of fruit and vegetables. Eur J Clin Nutr 54, 706-714.

42. Arimond M, Wiesmann D, Becquey E et al. (2010) Simple food group diversity indicators predict micronutrient adequacy of women's diets in 5 diverse, resource-poor settings. J Nutr 140, issue 11, 2059S-2069S.

43. Foote J, Murphy S, Wilkens L et al. (2004) Dietary variety increases the probability of nutrient adequacy among adults. J Nutr 134, 1779-1785.

44. Ogle B, Hung P \& Tuyet H (2001) Significance of wild vegetables in micronutrient intakes of women in Vietnam: an analysis of food variety. Asia Pac J Clin Nutr 10, 21-30. 